\title{
CREACIONES PRODIGIOSAS: DISCIPLINAS ESCOLARES E HISTORIA DEL CURRÍCULUM
}

\section{Marvelous Creations: \\ School Subjects and Curriculum History}

\author{
Raimundo CUESTA \\ Fedicaria-Salamanca \\ Correo-e: raicuesta2@gmail.com
}

Recibido: 8 de septiembre de 2020. Envío a informantes: is de septiembre de 2020.

Aceptación definitiva: 3 de febrero de 202I

RESUMEN: El currículum y las disciplinas escolares no tienen esencia, tienen historia. Su evolución semántica a lo largo del tiempo muestra que el reciente giro metafórico y contextual de la historia de los conceptos ayuda a comprender mejor, evitando el anacronismo, la complejidad y la polisemia de ambos términos. Currículum y disciplina son vocablos que, junto a «civilización», «cultura» y «educación», entre otros, constituyen parte del orden conceptual de la razón moderna. Desde hace décadas, la historiografía del currículum y de las disciplinas escolares, empujadas por tradiciones académicas y culturales diferentes en el mundo anglosajón y en el europeo meridional, han perfeccionado notablemente la explicación de las peculiaridades del conocimiento escolar. A caballo entre ambas tradiciones, la idea de código disciplinar, acuñada por el autor de este artículo, vino a ser una palanca heurística para lograr una comprensión histórica y crítica del currículum y de esas criaturas prodigiosas de la cultura escolar que denominamos asignaturas.

Palabras Clave: disciplinas escolares; historia del currículum; código disciplinar; cultura escolar; historia genealógica; conocimiento escolar.

Aвstract: Curriculum and school subjects do not have a fixed essence, they have history. The evolution of their meaning over time shows that the recent metaphorical and contextual turns we have seen in conceptual history help to avoid anachronisms and to better understand the complex and polysemic nature of those terms. Curriculum and disciplina, like inter alia «civilization», «culture» and «education» are part and parcel of the conceptual order in modern reason. For decades curriculum and school subjects historiography, although driven by different 
academic and cultural traditions in the Anglo-Saxon and the Southern European spheres, has gone a long way toward explaining the specificities of school knowledge. Between the two traditions, the idea of a subject or discipline code [código disciplinar], coined by the author of this article, became a heuristic tool to understand, from a historical and critical perspective, the curriculum and those marvelous creatures of school culture which we call school disciplines or subjects.

KEY WORDS: school subjects; curriculum history; subject or discipline code; school culture; genealogical history; school knowledge.

\section{Prenotandos}

$\mathrm{L}$

A HISTORIA DE LAS DISCIPLINAS ESCOLARES constituye una porción de la historia del currículum y, por extensión, de la educación y de la cultura; por lo demás, su estudio se inscribe en la historia social del conocimiento, o sea, dentro de la pesquisa acerca de la sociogénesis de su selección, distribución y apropiación en contextos escolares. Por añadidura, las materias de enseñanza son semejantes a prodigiosas criaturas que, por más que se presenten con el rostro sonriente de «lo natural», poseen, como las cosas y las palabras que les dan nombre, una artificiosa y evanescente evolución de significados, siempre atravesados por el carácter metafórico inherente a toda narrativa histórica y a todo lenguaje humano ${ }^{\mathrm{I}}$.

Para Nietzsche, «las verdades son ilusiones que se han olvidado que lo son, metáforas que se han vuelto gastadas» ${ }^{2}$. En efecto, currículum y disciplinas escolares son expresiones que materializan «ilusiones» de efigie borrosa, y que finalmente han devenido en metáforas congeladas que, cual monedas herrumbrosas, han perdido su brillo originario y han quedado cosificadas en sus actuales nichos institucionales. Justamente la historia crítica y genealógica, dentro de la que quiere inscribirse este trabajo, mira los objetos de investigación, las palabras y los discursos que los envuelven, acudiendo a ese método de la sospecha de raíz nietzscheana conforme al cual nada es lo que parece y solo una historia del presente, esto es, una genealogía problematizadora de nuestra actualidad, facilita la capacidad de destruir la coraza que protege las relaciones de poder disfrazadas de conocimiento desinteresado. La falta de transparencia de la realidad y la ambigüedad

Véase Blumenberg, H.: Paradigmas para una metaforología, Madrid, Trotta, 2003. Y también Fernández Sebastí́n, J.: «Metáforas para la historia y una historia para las metáforas», en GodiCheAu, F. y SÁnchez León, P. (eds.): Palabras que atan, Madrid, FCE, 20I5, pp. 9-62. En realidad, la variante metaforológica de la historia conceptual viene a acentuar y reforzar la dimensión histórica y no teleológica de los conceptos que sostienen y articulan cualquier área de conocimiento porque su evolución muestra a las claras su incompletud y contingencia.

NieTzsche, F.: «Sobre verdad y mentira en sentido extramoral», en Obras, Madrid, Gredos, 20I0, pp. 193-194. Por añadidura, el potencial del filo genealógico de Nietzsche ha sido parte sustancial de algunas de sus obras como Aurora. Reflexiones sobre la moral como prejuicio (I886) y Genealogía de la moral (1887). 
de su representación lingüística obliga, pues, a un escrutinio que siempre tenga en cuenta el trípode sustentante de la labor de la llamada historiografía conceptual, a saber, las variables y dinámicas concordancias entre las palabras, los significados y los referentes ${ }^{3}$. Y ello se procurará efectuar evitando el anacronismo y no olvidando jamás que el conocimiento escolar, además de su valor de uso o intrínseco, también posee valor de cambio, o sea, circula como capital cultural desigualmente apropiado por clases, géneros y otras subdivisiones sociales.

La historia conceptual y la mirada genealógica son enfoques que se pueden hacer complementarios desde un punto de vista crítico, esto es, desde un postulado metodológico que busca esos «residuos de metáforas» y que duda y pone en cuestión la cultura dominante y su forma de realización en las instituciones escolares, haciendo cierta aquella sentencia según la cual «la crítica no es una pasión del cerebro, sino el cerebro de la pasión» ${ }^{4}$. Estos supuestos nos ayudan a desnaturalizar la existencia de las materias de enseñanza, esas «prodigiosas» criaturas culturales, casi mágicas en tanto que producto de una trasmutación alquimísticas , que han ido tejiendo a lo largo de su existencia una red de significados dentro del edificio curricular erigido por el régimen de razón de la modernidad. Pero su espacio semántico se aloja dentro de otro más amplio y anterior presidido por conceptos matrices, una suerte de sustrato nutriente, como el trinomio civilización, cultura y currículum. Todos ellos, en cierto modo, se presentan como heraldos de la modernidad, pero no dejan de ser residuos de metáforas corroídas e irreconocibles, que tampoco pueden dejar de ocultar las miserias y penalidades que supuso su entronización.

\section{Civilización, cultura y currículum. Conceptos fundadores de la modernidad educativa}

El lenguaje en general, y el educativo en particular, se muestra como una entidad autorreflexiva: se refiere al contexto extralingüístico, pero también a sí mismo. Es, por consiguiente, factor constituyente y constituido. De ahí que la historia conceptual de civilización, cultura y currículum aluda a una cierta circularidad entre procesos sociohistóricos materiales e institucionales y juegos de lenguaje con poder performativo sobre la realidad misma, dotados siempre de sustratos

Es lo se llama, con razón, «doble trasparencia de la historia tradicional», a saber, la del texto respecto a la realidad histórica y la del texto del historiador respecto a sus intenciones historiográficas ya dadas. Véase Ankersmit, F. R.: Historia y tropología. Ascenso y caída de la metáfora, México, FCE, 20I4, p. 246.

4 Marx, C.: «Introducción para la crítica de la Filosofía del Derecho de Hegel», en Hegel, G. H.: Filosofía del Derecho, Buenos Aires, Claridad, 1986, p. II [pp. 9-22].

5 Esta imagen de la construcción de las disciplinas escolares como alquimia está muy presente, como se verá, en la obra de PopkewiTz, Th. S.: «The Alchemy of the Mathematics Curriculum. Inscription and the Fabrication of Child, American Educational Journal, n. ${ }^{\circ} 4 \mathrm{I}, 4$ (2004), p. 3 [pp. 3-34]. 
referenciales, pero también de una intensa impregnación metafórica. No en vano la metaforización envuelve cualquier forma de representar el mundo.

\section{I. Civilización}

Es fama que uno de los conceptos matrices de la modernidad es el de civilización, cuyo orto y primera expansión coincide con el terremoto de ideas que conmueve al mundo occidental entre mediados del siglo XVIII y la primera mitad del siglo XIX ${ }^{6}$. Es Francia el país en el que se localiza su primer uso a mediados del XVIII, cuando todavía, por ejemplo, en Voltaire o en la Enciclopédie, los vocablos más usuales eran police y politesse, contrapuestos a barbarie. Finalmente, en el siglo XIX se asienta el sustantivo primero en Francia y desde allí, a mitad del siglo XIX y casi al mismo tiempo, se extiende por las distintas lenguas 7 .

En su entorno se genera una constelación de palabras, sucesos históricos y categorías conceptuales que explican el decurso del mundo occidental. En cierto modo, su gestación representa la autoconciencia de superioridad de Occidente, uno de los componentes principales del prisma con el que se mira (y se domina) al otro, primero como una operación interna (civilizar o sacar de la ignorancia mediante la educación a los naturales del propio país), después como una magna operación externa de tipo colonial (sacar del salvajismo a los pueblos sin historia). Siempre próximo a educación, a ilustración y, de manera más o menos conflictiva según los países, a cultura. Indica la suprema realización de la vida social organizada y se convierte, al decir de Fernández Sebastián, en una suerte de concepto-recipiente, que pasa de expresar la acción de suavización, pulimento y devastación de la rudeza de las costumbres al fenómeno de abandonar la barbarie y alcanzar un mayor grado de desarrollo en la evolución socials. Ya se entenderá que su estrecho parentesco semántico con la idea de progreso, con la nueva concepción de la filosofía de la historia y, en suma, con los valores e ideales del siglo XVIII ni es caprichoso ni fruto del azar.

El origen y primera difusión del concepto, como todos los de la constelación ilustrada, plasma el momento de ascenso de la burguesía desde mediados del siglo XVIII, cuando los discursos de la emergente sociedad disciplinaria se mezclan con los proyectos de transformación política, social y económica del Antiguo

6 Reinhardt Koselleck, uno de los fundadores de la historia conceptual, dio el nombre de Sattelzeit a ese periodo de aceleración histórica entre dos siglos, inherente a las grandes transformaciones que dieron vida a la modernidad. Véase Koselleck, R.: Futuro pasado. Para una semántica de los tiempos históricos, Barcelona, Paidós, 1993.

Álvarez Miranda, P.: Palabras e ideas: el léxico de la Ilustración temprana en España, Madrid, Real Academia Española, 1992, p. 396. También información complementaria y no del todo coincidente en Mudrovcic, M. I.: Historia, narración y memoria. Los debates actuales en filosofía de la historia, Madrid, Akal, 2005.

8 Fernández Sebastián, J.: «Civilización», en Fernández Sebastián, J. y Fuentes, J. M.: Diccionario político y social del siglo XIX español, Madrid, Alianza, p. I47 [pp. I44-I56]. 
Régimen. Aquí cambio histórico y cambio conceptual caminan de la mano alimentándose uno a otro, y ese mundo en mutación tiene su centro de gravedad en Francia, de lo que da cuenta el hecho de que el francés fuera a la sazón la lengua culta por excelencia de las clases superiores de toda Europa. Tras la Revolución francesa, el término se convierte en la expresión de la autoconciencia nacional y, a partir de las campañas de Napoleón en Egipto, empieza a actuar como ideología justificadora de la dominación colonial, proyectándose hacia afuera.

Lo cierto es que en la Ilustración cuajan y se elaboran complejas teorías sobre el desarrollo y perfeccionamiento social como progreso civilizador, cuya fuente de alimentación sería siempre la educación de los pueblos. La educación: Thats's the question.

\subsection{Cultura}

Pero en materia de educar, en asuntos curriculares, entra otra noción en el escenario, a saber, cultura. La sustantivación del término cultura y su nuevo significado, diferente al de su prístina etimología latina (colere, cultus), solo tiene lugar en el siglo XVIII, cuna, como dije, de las grandes metamorfosis semánticas del nuevo tiempo histórico de la modernidad. Inicialmente el sentido de la palabra latina tiene que ver con habitar, cultivar, cuidar, honrar, etc., y su desenvolvimiento posterior gira en torno a la idea de cultivo agrícola y desarrollo natural, pero también de cuidado de algo o veneración por alguna cosa. Durante su trascendental mutación dieciochesca comparte espacio semántico con civilización, momento en el que la palabra deja de estar atada al mundo agrícola y se vincula al de la producción de bienes espirituales, modos de vida e ideales de formación de las personas.

Norbert Elias ha explicado brillantemente la curiosa sociogénesis de civilización y cultura como dos vías nacionales (francesa y alemana) del ascenso de la burguesía9. Así, Kultur se constituye en palabra-emblema de la localista y débil burguesía alemana (como reacción romántica e idealista frente al cosmopolitismo afrancesado) y se construye como réplica conceptual. En Alemania las clases medias dedicadas al trabajo intelectual se refugian en la cultura, en su principal capital frente a la aristocracia, para confeccionar un ideal de nacionalidad alemana y de formación: la Bildung o cultivo de una personalidad total. Tal aspiración conduce al cultivo de los valores espirituales propios e intransferibles de cada pueblo y cada individuo mediante una lectura e interpretación de los textos canónicos del mundo clásico. Por lo demás, esta bifurcación conceptual no dejará de tener consecuencias transcendentales a la hora de fundar y desarrollar las tradiciones académicas y curriculares en los sistemas educativos de Francia y Alemania.

Al final, tras el accidentado acaecer del mundo contemporáneo, presenciamos una victoria relativa de la cultura frente a civilización (palabra que actualmente

9 Elias, N.: El proceso de la civilización. Investigaciones sociogenéticas y psicogenéticas, México, FCE, 1988. Obra maestra cuya factura se remonta a los turbulentos años treinta del siglo pasado. 
no es de buen tono después de la larga historia colonialista). En un caso y otro, con diferentes intensidades nacionales, el mundo de la cultura, el de los bienes espirituales como el de la educación, siempre ha fabricado un escudo protector para esconder más realidades de las que enseña, porque el «misterio de la cultura» consiste precisamente en su evanescencia y efecto encubridor de realidades que se alojan, como ocurre en la educación en tanto que parte de la cultura culta, en su trastienda.

\subsection{Currículum}

Se diría que civilización y cultura sirven a modo de conceptos matrices dentro de los que comparece y convive históricamente nuestra actual representación mental de educación y currículum. Ambos significantes, provenientes de la lengua latina (respectivamente, de educatio y de la sustantivación del verbo currere), terminan erosionando su prístino significado (respectivamente, «crianza» y «correr/ carrera»), que resulta muy distinto al actual, quedando solo la cáscara, una especie de vaga huella semántica de una metáfora que hoy se emplea para referirnos a las características de un tipo de enseñanza pública (fuera del hogar familiar), reglada, jerarquizada y férreamente disciplinar. El itinerario de esta mutación, que se remonta al siglo XVI europeo, discurre en paralelo a los primaverales brotes de una modernidad que, desde entonces, siempre ha alumbrado una pareja indestructible: la libertad y su contrario. Por lo tanto, en Europa entre los siglos XVI y XVIII se experimentan los primeros pasos, si bien lentos y a veces contradictorios, hacia la escuela como mecanismo público de conquista de almas y ortopedia de cuerpos. Este fenómeno alcanzara su máxima expresión con la edificación y generalización en Occidente, a menudo a cargo del Estado, de los sistemas educativos nacionales durante el siglo XIX, cuyos modos de organización pedagógica y lenguajes representativos se heredan de las distintas doctrinas cristianas. Y así ya en el siglo XVIII, siglo pedagógico por excelencia, educación aludía a algo parecido a un concepto-promesa de la razón moderna, que pugna por depositar en el imaginario social una expectativa de felicidad, progreso y redención social a través de la escuela ${ }^{\mathrm{IO}}$. Algo semejante ocurrió con Pedagogía que, convertida en conocimiento experto sobre la educación, desde su origen dieciochesco, contiene un compromiso de salvación mundana bajo los luminosos imperativos de la Ilustración ${ }^{\text {II }}$.

1o Para un desarrollo más extenso del concepto, véase mi artículo CUESTA, R.: «Genealogía y cambio conceptual. Educación, historia y memoria», Archivos Analíticos de Políticas Educativas, vol. 22, n. ${ }^{\circ} 23$ (20I4), pp. I-26. Y, desde luego, la clásica reflexión de LeRENA, C.: «Educación», en DeL CAmPO, S.: Tratado de sociología, vol. 2, Madrid, Taurus, 1988, pp. 97-I45.

" Véase Vilanou Torrano, C. y Laudo Castillo, X.: «La historia conceptual en la historiografía de la educación. Hacia un estudio del pensamiento pedagógico", Encounters/Encuentros/ Encontres, n. ${ }^{\circ}$ I5 (20I4), pp. I6I-I80. Estos autores insisten, con buen criterio, en el carácter a la vez salvífico y mundano de la Pedagogía en sus orígenes, rasgo que se puso a disposición de la construc- 
En ese transcurrir, que levanta las vigas maestras de la educación pública, se acumulan, como una suerte de metáforas fosilizadas, o sea, como conceptos que, olvidando su traza originaria, todavía hoy comparecen como residuos de tropos, aludiendo vagamente a su primera historia: la educación como crianza y nutrición; el currículum como pista circular de carreras. Así la palabra currículum, que ab origine evocaba el atletismo clásico, deviene en metáfora para indicar el camino que había de cursar un estudiante. También cabe mencionar que otras voces, como Gymnasium, que originariamente connotaban prácticas de ejercitación física, y que acabarán pasando a ocupar un lugar notable en el orbe léxico de la nueva educación. Quizás se pueda adivinar la existencia, detrás de todo este discurrir, de una formación conceptual incompleta, de eso que Hans Blumenberg llamaría «metáforas pre-conceptuales», o, más bien, simplemente haya de suponerse que se trata de fosilizaciones de un estrato semántico más vetusto ${ }^{12}$.

En lo referido a currículum, en realidad, como también ocurre con educación, su carga semántica reconstruida de nuevo cuño durante la modernidad hace que ambos vocablos se comporten como verdaderos neologismos, como viejas-nuevas palabras que obedecen a necesidades extralingüísticas muy diferentes a las que les dieron vida inicialmente. Este no es ni mucho menos un caso excepcional, tal como ha demostrado la metodología empleada por los historiadores de los conceptos. Sin pertenecer a ese gremio profesional, ya en su día, al estudiar la genealogía del término currículum, S. Kemmis alertaba acerca de los peligros que entraña el anacronismo de quienes usan ese vocablo con el sentido conceptual de nuestro tiempo antes de que surgiera como tal la realidad que designa. Al parecer, fue en 1633 , en la Universidad de Glasgow, bajo la irradiación calvinista, cuando se registra un primer uso moderno ${ }^{13}$.

En realidad, como aprecia D. Hamilton, el momento de aparición de currículum no es casual. Nace y coincide con una sucesiva cadena de cambios pedagógicos ( $y$ de otro estilo) habidos en el siglo XVI, los cuales primero inciden en el orden disciplinario y la graduación de la educación (división por niveles o grados en clases distintas), y luego se acompañan de una mayor complejidad en los métodos y los contenidos de enseñanza, todo ello en el contexto de una primera expansión de los usuarios de la educación. De modo que la noción de currículum como secuencia estructurada conforme a un particular régimen disciplinario pro-

ción de una suerte de discurso perenne y redundante al servicio de una «utopía temporal a realizar en la tierra» (p. I70).

I2 Blumenberg, H.: op. cit.; y también en Rivera García, A.: «Hans Blumenberg: mito, metáforas absolutas y filosofía», Ingenium, n. ${ }^{\circ} 4$ (2010), pp. I45-165. Por otra parte, como ya indicamos, para Nietzsche «conocer es operar con las metáforas predilectas». Véase NieTzsche, F.: El libro del filósofo, Madrid, Taurus, 1970, p. 91.

${ }_{13}$ Kemmis, S.: El currículum: más allá de la teoría de la educación, Madrid, Morata, 1988, pp. 3132. Como veremos más adelante, la cosa no es tan sencilla como la presenta Kemmis cuando afirma que los jesuitas desde finales del siglo XVI utilizarán disciplina para designar los cursos académicos. En realidad, el contenido de la Ratio Studiorum (I599) no autoriza esa opinión. En la Ratio para designar los cursos académicos no se acude a disciplina y sí a classis, cursus e incluso a gradus. 
pio de las instituciones educativas posee un ascendiente calvinista escocés, que combina orden social con el disciplinario de estudios, regímenes de razón y de disciplinamiento social anunciadores de la institución escolar de la modernidad ${ }^{14}$.

No obstante, siendo cierto que el contexto subyacente de currículum fue la expansión en Europa de una educación cada vez más regulada, disciplinada y al servicio de la conquista de las almas, sin embargo, ello no fue una exclusiva del mundo calvinista. En efecto, frente a la tendencia a concebir las religiones reformadas como motor de todo atisbo de modernización de Occidente, hay que subrayar que ese fenómeno, con matices y ritmo propios, también ocurrió en el mundo católico, muy especialmente con la Ratio Studiorum (I599) ${ }^{15}$. El invento jesuítico, contraparte pero imagen viva de los calvinistas en el mundo católico, constituye a la vez un plan de estudios y un régimen reglamentario. Esta ratio nada tiene que envidiar al universo conceptual que se va adhiriendo a la palabra currículum compartido mediante los mismos u otros vocablos a pesar de surgir en un mundo religioso dogmáticamente discrepante ${ }^{16}$.

El terremoto teológico y religioso que sacudió a Europa en el siglo XVI se comporta como el útero dentro del que se gesta un nuevo pensamiento educativo que adelanta las virtudes de la escuela pública al servicio del cuidado de las almas y la contención de los cuerpos, superando el estrecho horizonte del hogar familiar, encargado hasta el siglo Xvi del adiestramiento de la infancia mediante procedimientos fundados en la cultura empírica de las clases populares, a menudo analfabetas y teñidas de una tenue, rudimentaria e irregular religiosidad. En ese marco de violentas mutaciones religiosas del siglo XvI, comparecen los nuevos lenguajes educativos (con el consiguiente batallón de metáforas de compañía) del

${ }^{14}$ Hamilton, D.: "Orígenes de los términos educativos "clase” y "currículum" , Revista de Educación, n. 295 (1991), p. 204 [pp. 187-205].

is La tendencia a considerar una vía unidireccional en los procesos de modernización en Occidente acude demasiado a menudo a un razonamiento ex post facto. Y así, como sea que Estados Unidos con el tiempo se ha alzado hasta la cima del poder del mundo occidental, se lee la historia de la Edad Moderna como el precedente necesario del triunfo de un modelo de escuela y de currículum de impregnación protestante reformada. En España Álvarez-URía, F.: El reconocimiento de la bumanidad. España, Portugal y América Latina en la génesis de la modernidad, Madrid, Morata, 20I4, tomando como ejemplo el discurso en defensa del indio americano de la Escuela de Salamanca del siglo Xvi llevado a América por los dominicos, defiende la existencia en España, Portugal y América Latina de una «modernidad latina» estrechamente vinculada al debate teológico-político ocasionado por la conquista y colonización del Nuevo Mundo.

${ }_{16}$ Ciertamente, curriculum no figura en el texto latino de la Ratio Studiorum (I599), pero sí un elenco de voces que ordenan un universo conceptual semejante al calvinista, entre otros: disciplina, materia, classis, cursus, ratio, doctrina, facultas, materia, schola, gradus, aula... Todos ellos convecinos del léxico emergente de la educación de la modernidad. En el caso de disciplina, como ya se sugirió, lo hace de forma insegura y un tanto ambigua, ya que su empleo se verifica como sinónimo de materia (tema u objeto de estudio), pero también con el significado de orden de las clases (las clases como espacio físico, como división graduada de la enseñanza y a veces como las lecciones que se dan in scholis). Véase al respecto la versión bilingüe de la Ratio Studiorum que he manejado y que ha sido traducida al castellano por A. Díez Escanciano, en GIL, E. (ed.) et al.: El sistema educativo de la Compañía de Jesús, Madrid, Universidad Pontificia de Comillas, 1992, pp. 59-303. 
protestantismo reformado a los que alude por extenso Daniel Tröhler ${ }^{17}$, que sin género de dudas propulsan con una nueva fuerza a la escolarización fuera de los círculos domésticos. Precisamente en el bumus de esa trascendental y larga coyuntura histórica, que pone los cimientos de la racionalidad moderna, fermenta en el mundo calvinista el término currículum, dotado, eso sí, de un nuevo sentido y, si seguimos las pautas explicativas del relativamente reciente giro metafórico de la historiografía postmoderna, tal fenómeno quedaría inscrito y explicado dentro de «la estructura fundamentalmente metafórica de la narrativa histórica que establece una interacción entre lo narrado y lo realmente acontecido» ${ }^{18}$. Así el valetudinario significado del término currículum (carrera) desemboca ahora progresivamente en mero tropo herrumbroso que pretende dibujar ideas y realidades institucionales innovadoras.

En realidad, en el ámbito católico europeo, en dura competencia con las Iglesias reformadas, se manejaron ideas educativas y términos que poseían una cierta vecindad semántica con currículum, no en vano el proceso de construcción de la escolarización como arma civilizadora y salvadora del alma fue común a ambos. Entre ellos me interesa destacar a continuación el caso de disciplina. Discipline está en el corazón mismo del pensamiento de Calvino y de toda la modernidad mucho antes de su traslado y transfiguración dentro de los sistemas educativos del mundo contemporáneo bajo la especie emblemática de disciplinas escolares.

\section{De disciplina a disciplinas escolares: una mutación consecuencia de la generalización de los sistemas educativos}

Se mire como se mire, currículum/disciplina constituye una pareja de hecho, una asociación terminológica inseparable y más o menos expresamente institucionalizada desde el siglo xvi. Sin duda, disciplina actúa como heraldo, como palabra-emblema representativa de la emergencia discursiva de la razón moderna, símbolo también de la primera modernidad educativa fraguada en Europa durante las postrimerías del llamado Renacimiento. Si bien es cierto que, como ya se indicó, la noción de currículum como secuencia estructurada posee una ascendencia calvinista, el paralelo y mucho más amplio proceso de «disciplinamiento social» que entroniza el vocablo disciplina viene ligado en la Europa del siglo XVI a un genuino y trascendental fenómeno de recristianización y confesionalización, o sea, a una magna obra de salvación de almas y de cirugía de subjetividades normalizadas conforme a la ortodoxia religiosa impuesta en cada territorio ${ }^{19}$.

${ }_{17}$ TRÖHLER, D.: Los lenguajes de la educación. Los legados protestantes en la pedagogización del mundo, las identidades nacionales y las aspiraciones globales, Barcelona, Octaedro, 20I3. El uso que Tröhler da a «lenguajes» podría asemejarse, más o menos, al de «paradigma», «visión del mundo», «ideología», «tipo ideal», «cultura» e incluso al foucaultiano «régimen de verdad».

18 Fernández Sebastián, J.: op. cit., p. 43.

19 Al respecto, es muy conocida la perspectiva foucaultiana de libros, ya de obligada lectura, como Vigilar y castigar, pero no debe olvidarse mencionar la tradición investigadora de la Socialdis- 
Tras las guerras de religión que asolaron Europa, la autoridad política consiguió en la Paz de Augsburgo (1555) la atribución de elegir libremente el culto a seguir por unidad estatal y, por ende, la obligatoria aceptación entre sus súbditos de acuerdo con la sentencia cuius regio, eius religio. Tanto en el orbe católico como en el protestante, desde entonces hasta la guerra de los Treinta Años (I6I8-I648), se vive una auténtica carrera entre los diferentes credos religiosos y bajo el amparo del poder político, por la colonización de almas y el consiguiente control de la observancia religiosa de las familias y de los individuos. A tal fin se dispone una compleja maquinaria de control y supervisión que supone la sólida articulación de cada confesión religiosa sobre su jurisdicción geográfica de intervención: curias diocesanas, tribunales episcopales, registros parroquiales, visitas pastorales y diocesanas, congregaciones colegiales, misiones, ejercicios espirituales, catequesis, distribución de parroquias y escuelas por todo el territorio ${ }^{20}$. Esta proliferante retícula institucional extendida sobre el espacio de soberanía del Estado busca la forja de comportamientos de sumisión de las poblaciones a normas políticas y religiosas más estrictas, censando el número de los habitantes y su ubicación, controlando así su vida desde la cuna a la tumba, como real y simbólicamente hacen los registros parroquiales. Por lo demás, solo la alianza del poder político y el religioso hizo posible tan gigantesca obra de reeducación y conducción de subjetividades. Nada debe sorprender que la escolarización, todavía incipiente pero ya in crescendo, constituya una de las vetas más provechosas de este colosal dispositivo de disciplinamiento social.

Desde la Universidad hasta las escuelas parroquiales y municipales pasando por los colegios jesuitas, los Gymnasium protestantes o similares, todo el emergente sistema educativo de la primera modernidad sufre transformaciones tanto en el contenido de la enseñanza como en los métodos de transmisión. El eje de esta mutación sitúa a la disciplina en el altar mayor, en tanto que código pedagógico subyacente y modelo de organización de las nuevas enseñanzas y de los renovados lenguajes educativos. En realidad, el rasgo definitorio de cursus o currículum del siglo XVI no era su contenido (que derivaba de los textos de los autores empleados) ni su organización ni su ordenación, muy distintos a nuestras

ciplinerung alemana, que ha tenido un notable seguimiento en Italia. Para un estado de la cuestión sobre este tema, véase MANTECÓN, T. A.: «Formas de disciplinamiento social, perspectivas históricas», Revista de Historia Social y de las Mentalidades, vol. I4, n. ${ }^{\circ} 2$ (2010), pp. 263-295. Por lo demás, sobre el significado del Estado Moderno todavía sigue siendo imprescindible la obra del historiador portugués Hespanha, A.: Vísperas de Leviatán, Madrid, Taurus, I989. Véase también la aplicación de tales categorías en Hernández SÁnchez, G.: «Disciplina colegial y desórdenes estudiantiles en la Salamanca del Siglo de Oro», en Correa BALlester, J. (coord.): Universidad y sociedad: historia y pervivencias, Universitat de Valéncia, 2018, pp. 279-295.

${ }_{20}$ Para una excelente descripción de todo este movimiento disciplinante, véase Palomo, F.: «Disciplina Christiana. Apuntes historiográficos en torno a disciplina y disciplinamiento como categorías de la historia religiosa de la alta Edad Moderna», Cuadernos de Historia Moderna, n. ${ }^{\circ}$ i8 (1997), pp. II9-136. 
asignaturas escolares ${ }^{21}$, sino el entonces novedoso afán ordenancista y regulador a través de la disciplina («la que encamina al discípulo a que siga con diligencia la doctrina y preceptos del maestro", se dice ya en el Vocabulario del hispano Alonso de Palencia de 1490$)^{22}$. Y sobre todo abrió un torrente discursivo sobre las formas metódicas y organizativas de disposición del espacio y uso del tiempo, anchuroso cauce que no hace más que ampliarse y proseguir hasta fundar ya en el siglo XIX una sistemática pedagogía del orden y la comunicación dentro de las clases conforme a lo que se ha denominado «sistema aula», triunfante de manera definitiva en la centuria decimonónica.

En realidad, disciplina, como otras categorías manejadas en la cultura occidental, no posee una esencia intemporal, y su creación, en cambio, es consecuencia de la elaboración de un artificio humano cuya etimología nos ayuda a distanciarnos de su uso habitual. Nos inclina a desnaturalizar su esencia y a señalar su carácter un tanto prodigioso. En su origen los términos latinos disciplina y discipulus (de discere, aprender), y sus derivados como disciplinatus, aluden a situaciones relacionadas con la educación (discípulo, aprendiz, instruido) ${ }^{23}$. Repárese en que docilis es el que fácilmente aprende y docilitas es la facultad de aprender. De aprender, o sea, de ser instruido en una doctrina. Sea como fuere, en el Cinquecento tendría lugar, como se ha sugerido páginas arriba, una surte de «movimiento «disciplinario» $[\ldots]$ en las escuelas, las universidades y las iglesias ${ }^{24}$. Esta implacable proclividad hacia un orden disciplinario sistemático asoma también, como ya se indicó, en el origen calvinista de currículum como método reglamentario más racional y ordenado. Por supuesto, la Ratio Studiorum (I599) se encuentra también envuelta por esa imparable ola clasificatoria y disciplinaria de la población a través de la naciente voluntad de escolarización. En el texto latino originario de la vulgata pedagógica de los jesuitas constan vocablos como disciplina, materia, cursus, ratio, classis, examen, facultas, ars, scientia, professor, magister, gymnasium y otros. Por lo que hace a disciplina, es curioso observar cómo en la genuina versión latina y en la traducción que he manejado el vocablo oscila entre un abanico de significaciones que va desde el parecido con materia (al que el traductor acude con frecuencia) hasta la proximidad con orden de las clases (classis se emplea como

${ }^{21}$ Hamilton, D.: «Notas desde aquí y ahora. Sobre los inicios de la escolarización moderna», en Popkewtiz, Th.; Frankin, B. y Pereyra, M. Á. (comps.): Historia cultural y educación. Ensayos críticos sobre conocimiento y escolarización, Barcelona, Pomares, 2003, p. 195 [pp. 187-207].

22 Alonso, M.: Diccionario medieval español, Salamanca, Universidad Pontificia de Salamanca, 1986, p. 959 .

${ }_{23}$ En Covarrubias, S.: El Tesoro de la Lengua Castellana, de i6ir, se dice: «El mismo nombre es latino, disciplina, ars, doctrina...». Y añade: «Disciplinable el dócil y apto para ser enseñado». Disponible en http://www.fondosdigitales.us.es/books/765/tesoro-de-la-lengua-castellana-o-española.pdf

${ }_{24}$ Burke, P.: Historia social del conocimiento. De Gutenberg a Diderot, Barcelona, Paidós, 2002, p. I22. 
división graduada, pero también como espacio-aula), pasando por algo semejante o contiguo a la capacidad de entendimiento (facultas) ${ }^{25}$.

En la magna obra jesuítica cuando se utiliza disciplina se incide en su carga coactiva más que en su faceta de saber escolar. Para lo que hoy, forzando las semejanzas, llamaríamos disciplinas escolares o asignaturas se suele recurrir a scientia (a veces ars); y todo parece indicar que las asignaturas o materias escolares todavía no han recibido su definitivo bautismo y posterior confirmación, que solo culminarán en el curso de la formación de los sistemas educativos y su ulterior desarrollo en los siglos XIX y Xx, momento en el que se «inventan» y progresivamente se institucionalizan las disciplinas académicas y escolares ${ }^{26}$. Entonces crece la cercanía entre currículum y disciplinas escolares, entendidas estas como el cultivo sistemático y reglado de las facultades más importantes de la mente, aunque el concepto de conocimiento escolar disciplinado acabará designándose en cada lengua con sintagmas particulares hijos de cada tradición cultural y lingüística, por ejemplo, disciplines scolaires en francés o school subjects en inglés, etc. Ahora bien, como advirtió D. Julia en su día, sería un colosal anacronismo y un vano intento buscar disciplinas escolares como las que hoy conocemos antes de la progresiva creación de los sistemas educativos del siglo $\mathrm{XIX}^{27}$. Desde luego, en Francia «las distintas materias que se imparten hoy en la enseñanza secundaria se empezaron a designar con el nombre de «disciplinas» después de la Primera Guerra Mundial $»^{28}$. Siendo así que todavía hasta finales del siglo XIX se asimilaba lo disciplinar al orden interno y la policía de los centros docentes y solo se abrió paso otro valor semántico cuando empezó a unirse, mediante el término disciplina escolar, el dominio de los contenidos de enseñanza a un cierto tipo de ejercicio y adiestramiento de la mente. A partir de ahí el abanico de asignaturas cobra el pleno sentido actual de «disciplinas escolares». Ocurre, pues, que, en este caso, antes fue la realidad y el concepto que la palabra que los diera vida más conti-

25 Ratio: op. cit., pp. 69 y 67.

${ }_{26}$ Y, como señala GOODSON, I.: op. cit., p. 70, se sacraliza «la suposición de que el curriculum debe ser académico y asociado a las disciplinas universitarias (lo que) es una situación que no tiene nada de normal o "dada”». Justamente la compleja relación entre disciplinas académicas y escolares es una de las cuestiones claves de la historia del currículum.

${ }_{27}$ Julia, D.: «La construcción de las disciplinas escolares en Europa», en RuIz BerRio, J.: La cultura escolar. Tendencias históricas emergentes, Madrid, Biblioteca Nueva, 2000, pp. 45-78.

28 Chervel, A.: «Historia de las disciplinas escolares. Reflexiones sobre un campo de investigación», Revista de Educación, n. ${ }^{\circ} 295$ (I99I), p. IO2 [pp. 59-II]. En España el término «asignatura» es el que se emplea desde los primeros planes de estudio y en la mayoría de las fuentes de la burocracia educativa del siglo XIX (programas, memorias, certificaciones escolares, etc.). Todavía en SÁNCHEZ SARTO, L.: Diccionario de Pedagogía, Barcelona, Labor, vol. I, 1936, p. 922, impera el significado casi exclusivo de orden y vigilancia para el logro de ciertos valores propios de la escuela. Sin duda, la vigencia de «asignatura» llega hasta nuestros días, aunque su uso se combina cada vez más frecuentemente con el de «materia», mientras que el término «disciplina escolar» comparece raramente en el uso diario del lenguaje y en los documentos, y solo se hace fuerte en el campo de la investigación historiográfica desde los años noventa del siglo pasado. En todo caso, el concepto de un saber disciplinar ya está presente en las asignaturas de los primeros planes de estudio que, desde mediados del siglo XIX, regulan la educación española. 
nuada. Todo ello a pesar de que, como se vio, ese significado ronda a la palabra disciplina y, en cierto modo, a currículum desde la temprana Edad Moderna, pero ciertamente, el orden de las materias escolares de nuestro tiempo no es una mera consecuencia «necesaria» del ayer. Es, como veremos, una construcción conflictiva de saberes y poderes con rasgos propios. Y tampoco cabe olvidar, en la senda de la historia conceptual, que las palabras nacen de las cosas, pero que, en cierto modo, las cosas nada son al margen de las palabras que las hacen, que las tornan humanas. Veamos ahora cómo los historiadores se han hecho cargo de este fenómeno.

\section{Un peculiar fruto del invernadero escolar: las disciplinas escolares. Miradas historiográficas entre lo social, lo discursivo y lo cultural}

De lo dicho hasta aquí se infiere que la dimensión metafórica que impregna el devenir del concepto «disciplinas escolares» es coexistente y complementaria de la que acompaña a currículum, si bien la historia de ambos rótulos a veces ha servido a los historiadores como designación de campos específicos de estudio (especialmente en el mundo anglosajón), no del todo equivalentes, si bien con una existencia paralela. Ciertamente se trata de territorios complementarios, a menudo tangentes, siendo el primero de latitud mucho menos amplia que el segundo.

Por supuesto, partimos del supuesto según el cual el objeto «disciplinas escolares» no es una entidad material inerte, sencilla e inamovible, ni mucho menos una mera miniaturización de los saberes académicos. Por el contrario, el conocimiento que se genera en la escuela es fruto de un microclima compuesto por unas artificiales e idiosincrásicas condiciones de producción, selección y apropiación de saberes teóricos y prácticos. Así pues, los contenidos de enseñanza de los sistemas nacionales de educación constituyen, por proseguir con la alegoría, una suerte de cultura de invernadero, una criatura de eso que los historiadores franceses suelen designar «cultura escolar». Esta peculiar especie de planta consecuencia de la escolarización moderna se ha erigido en una importante faceta de la investigación histórico-educativa, principalmente desde los años ochenta del siglo pasado, que se ha materializado en un fluyente espacio discursivo compuesto por las dos orillas historiográficas (anglosajona y francesa) dentro de las que se enhebró mi propia pesquisa sobre la Historia como disciplina escolar, iniciada hace tres décadas. Sin embargo, primero con asombro y ahora ya con la naturalidad que da la costumbre de ver repetida una pauta de comportamiento, vislumbré que entre ambas riberas mediaba un vasto caudal de incomunicación, porque las dos se comportaban prácticamente como extraños que sin mirarse se ignoraban entre sí. Incomunicación, por otra parte, un tanto incongruente y hasta sorprendente si evocamos aquí las muchas y fructíferas interrelaciones científicas mantenidas entre la historiografía francesa derivada de la Escuela de los Annales, a través del patrocinio y amparo de la École des Hautes Études en Sciences Sociales (EHESS), y lo más pujante de la nueva historia cultural norteamericana, especialmente el 
rico cultivo de los seminarios en el Shebby Cullom Davis Center for Historical Studies de la Universidad de Princeton. Se ha dicho, con razón, que el «taller de París» y el «laboratorio de Princeton» alimentaron un intercambio que salvaba la separación física entre ambos polos ${ }^{29}$.

Empero la distancia se mantuvo en el campo de la historia de las disciplinas escolares. Y así, ese extrañamiento se evidencia de inmediato y de manera sumaria si alguien hace la prueba de comparar, evaluar y cruzar las citas y menciones bibliográficas que se efectúan en las indagaciones francófonas y anglófonas de ambas orillas. Por poner un ejemplo, en 1988 André Chervel publicaba una extensa y muy valiosa reflexión metodológica sobre el estudio de la historia de las disciplinas escolares, que llevaba cultivando desde hacía más de una década. Pues bien, allí solo hacía una leve referencia («une nouvelle tendence de l'histoire de l'éducation Outre-Manche») a Ivor F. Goodson para señalar la semejanza entre la noción inglesa de school subject y la francesa de discipline scolaire ${ }^{30}$. Pero conociendo la obra de los dos autores, sobresalientes ejemplares de lo que entonces representaba un territorio de pionera roturación, era evidente que el Canal de la Mancha significaba algo más que una brecha marítima entre los dos países. Por tanto, no se trataba de una cuestión de distancia espacial porque ya para entonces el británico I. F. Goodson (que por sistema dejaba de mencionar a la tradición francesa) había llevado con notable éxito, al otro lado del Atlántico, a Canadá y a Estados Unidos, sus averiguaciones sobre las materias de enseñanza. Al final, la irradiación mundial de este autor y de sus colegas norteamericanos fue muy superior a la de unos historiadores de la educación franceses quizás demasiado volcados hacia su propia tradición historiográfica. Ciertamente, como es sabido, el conocimiento es saber y viceversa, y el triunfo internacional del subcampo anglosajón de especialistas en historia del currículum no tiene solo que ver con el acierto o elegancia argumentativa de sus pesquisas, sino también con la presencia en plataformas muy poderosas (una de ellas la lengua) de difusión internacional del conocimiento. Seguramente una sociología histórica de las redes, nudos y polos de este subcampo vendría a confirmar que, no sin conflictos internos, el imperio de la norma investigadora de raíz anglosajona se ha ido imponiendo sobre cualquier otra ${ }^{31}$.

29 Véase Serna, J. y Pons, A.: La historia cultural. Autores, obras, lugares, Madrid, Akal, 2005. Aquí se expone con minuciosidad el entramado de saberes, encuentros, estancias de investigación y docencia y lugares institucionales que reúne a una selecta porción de historiadores culturales tales como los americanos Natalie Zemon Davis o Robert Darnton, los británicos Peter Burke o Lawrence Stone, el italiano Carlo Ginzburg o el francés Roger Chartier. Por no mencionar al antropólogo estadounidense Clifford Geertz, que desde los años setenta prestaba sus servicios en Princeton y cuya obra se convertirá en bandera del giro historiográfico hacia la antropología y la historia cultural.

30 Chervel, A.: «L'historie des disciplines scolaires. Reflexions sur un domaine de recherche», Histoire de l'éducation, n. ${ }^{\circ} 38$ (1988), p. 60 [pp. 59-119]. Texto capital que, gracias a los muy buenos oficios de M. Á. Pereyra, principal divulgador de la historia del currículum en España, vio la luz en España en el número 295 (1991) de la Revista de Educación.

${ }_{31}$ Esta es la pauta impuesta por algunos historiadores del currículum, que no se corresponde con la que gobierna a la mayoría de los historiadores de la educación americanos envueltos, según 
Tal hegemonía se ha conseguido en virtud de una curiosa selección y exclusión de fuentes intelectuales. Una de las paradojas más notables consiste en que una porción de esta tradición anglófona ha incorporado los planteamientos de M. Foucault a través de una peculiar lectura del pensador galo, mientras que sus homólogos franceses utilizan de manera muy diferente a su excelso compatriota. Valga como ejemplo la obra, ya muy internacionalizada, de Thomas S. Popkewitz, profesor en la Universidad de Wisconsin (allí donde se cruzan una parte de los caminos más influyentes de una de las vetas más sólidas de investigación) que rebasa muy ampliamente la historia de las disciplinas escolares y entronca con el terreno más extenso y sin fronteras prefijadas de la historia del currículum. Dejaremos que quizás algún día alguien se interne en el estudio de esta intrincada retícula de relaciones de saber-poder dentro de la que se fraguó la historia de las disciplinas escolares en estos dos mundos historiográficos impermeables entre sí. Y todo ello a pesar de que el propio Th. Popkewitz ha sido un abanderado de la necesidad de ofrecer la dimensión de historia comparada y la perspectiva transnacional. Claro que se presupone que tal dimensión ha de emplear como idioma-guía el inglés ${ }^{32}$. Desde luego, en mi propia indagación sobre la enseñanza de la Historia en España, iniciada en 1987, la lectura de I. F. Goodson fue todo un descubrimiento y también la de una porción sobresaliente de historiadores americanos del currículum, tales como como Th. Popkewitz o B. Franklin ${ }^{33}$.

En la otra galaxia, A. Chervel ha sido el máximo explorador y maestro indiscutible de la historia de las disciplinas escolares en Francia. En el ya citado artículo publicado en francés en 1988 (véase nota 30) y que vio la luz en España en I99I, decía: «Las disciplinas se merecen el máximo interés precisamente porque son creaciones espontáneas y originales del sistema escolar» ${ }^{34}$. Para entonces ya tenía tras de sí una muy apreciable cantidad de pesquisas sobre las materias de enseñanza. Empero, en un principio el concepto «cultura escolar» no está demasiado presente hasta 1998 cuando edita un libro que recopilaba toda una década de sus magníficas aportaciones sobre la historia de las materias de enseñanza, para el que opta por un título asaz sintomático: La culture scolaire. Une approche historique.

Popkewitz, en un style of reason de marcado acento historicista y de un culto acrítico a lo empírico, a los archivos. Sobre la denuncia de ese canon historicista, véase Popkewitz, Th. S.: «Styles of reason. Historicism, Historicizing and the History of Education», en Popkewitz, Th. S. (ed.): Rethinking the History of the Education. Transnational Perspectives on its Questions, Methods and Knowledge, New York, Palgrave Macmillan, 20I3, pp. I-26.

32 Popkewitz, Th. S.: «Historia transnacional comparada. Pensando en el yo y en el otro», Historia de la Educación, n. ${ }^{\circ} 36$ (2017), pp. 189-205.

33 Goodson, I. F.: Social histories of the Secondary Curriculum, New York, Philadelphia and London, The Falmer Press, 1985; y School Subjetcs and Curriculum Change, New York, Philadelphia and London, The Falmer Press, 1983. En esa excelente colección también contribuía PokewiTz, T. S. (ed.): The Formation of the School Subjects, New York, Philadelphia and London, The Falmer Press, 1987. Por lo demás, la traducción al castellano y la «normalización» de la obra de Goodson en España ocurre en los años noventa.

34 Chervel, A.: «Historia de las disciplinas escolares. Reflexiones sobre un campo de investigación», Revista de Educación, n. ${ }^{\circ} 295$ (1991), p. 69 [pp. 59-III]. 
Para entonces Dominique Julia, otro de los grandes fundadores de la historia de las disciplinas escolares en Francia, había dado una definición canónica publicada en $1995^{35}$.

La idea de microclima, de cultura de invernadero que, en cierta manera, exhala la noción de cultura escolar francófona, tiende a naturalizar o fijar el disciplinamiento del conocimiento escolar como un mal menor, como si fuera un sino inevitable para el mantenimiento de la estabilidad social o, dicho de manera, paradigmática: «Les disciplines sont le prix que la societé doit payer à sa culture pour pouvoir la transmettre dans le cadre de l'école ou du collège» ${ }^{36}$. Por supuesto, todo tiene un precio y también el historiador siempre ha de pagar alguno.

\section{El código disciplinar, una llave heurística para deshacer el encantamiento de las disciplinas escolares}

El historiador crítico debe ser consciente, como gustaba aseverar F. Nietzsche en su Genealogía de la moral (1887), de que toda realidad que dura mucho tiempo, como hoy ocurre con el menú curricular de las asignaturas escolares, se embebe de racionalidad hasta el punto de velar su origen y sus características históricas. Y así el conocimiento que se genera y alberga en las aulas no es una mera copia miniaturizada del conocimiento científico, porque, en realidad, constituye una construcción sociohistórica original que, sometida a presiones externas e internas, ha sufrido un delicado proceso de trasmutación alquimística, una magical tranformation, gracias a la labor mediadora de los dispositivos psicopedagógicos y otros factores operantes de la cultura escolar ${ }^{37}$. Por lo demás, la mirada sociológica descubre la artificiosidad de lo que se enseña en la escuela, ya sea apelando a B. Bernstein, que distinguía entre lo real (la carpintería) y lo «imaginario» (los trabajos en madera en las escuelas), ya sea atendiendo a P. Bourdieu, que, por su parte, confería al aprendizaje escolar la condición del «distanciamiento a lo real» por conllevar unas prácticas en sí mismas «gratuitas» $\mathrm{y}$ «desinteresadas» ${ }^{38}$.

En verdad, en el curso de cualquier pesquisa sobre cuestiones sociales conviene saber que una de las tareas más acuciantes y sustanciales consiste en construir el objeto de la misma, porque, frente a lo que es moneda corriente entre muchos

35 Chervel, A.: La culture scolaire. Une approche historique, Paris, Belin, I998. Julia, D.: «La culture scolaire comme objet historique», Paedagogica Historica, Supplementary Series (I) (1995), pp. 353-382.

36 Chervel, A. (1988): op. cit., p. iI9.

37 En una interesante entrevista, Th. Popkewitz reconocía la importancia en su obra de la alquimia como una intelectual tool para comprender cómo se efectúa el traslado y conversión del conocimiento científico en escolar. Véase Pereyra, M. Á.: «The Meanings of a Scholarship. An Intellectual Interview with Tom Popkewitz», en Pereyra, M. Á. y Franklin, B. M. (eds.): Systems of Reason and the Politics of Schooling, New York, Routledge, 20I4, pp. $85-86$ [pp. 67-IIo].

38 Bernstein, B.: Pedagogía, control simbólico e identidad, Madrid, Morata, 1998, p. 62. Y Bourdieu, P.: Meditaciones pascalianas, Barcelona, Anagrama, 1992, pp. 177 y 178. 
estudiosos, este no es una entidad inerte y dormida que permanezca ahí a disposición como si estuviera a la espera de la encantadora mano del príncipe que le despierte de su largo letargo. Tengo una total certeza de que sin herramientas teóricas no hay investigación histórica relevante, aunque siempre, parafraseando a P. Bourdieu, «la teoría sea como el aire que se respira» ${ }^{39}$ y no ha de comparecer como un parche superpuesto a una declaración de principios que se esgrima desde el comienzo de la investigación a modo de armatoste todo-lo-explica e inamovible. Precisamente en mi trabajo sobre las disciplinas escolares, código disciplinar, el concepto heurístico matriz, no se había elaborado previamente, sino que se urdió a lo largo del cuidadoso escrutinio y manejo de las fuentes. No estaba ab origine, pero, una vez que estuvo presente y su definición fue armándose progresivamente, cambió el sentido de la pesquisa al punto que me permitió pensar y ver el material empírico de otra manera, es decir, se convirtió para mí en una imprescindible herramienta cognoscitiva. ¿Cómo podemos delimitar el significado de tal instrumento heurístico?

Se puede definir como el conjunto de ideas, valores, suposiciones, reglamentaciones y rutinas de carácter expreso o tácito. En suma, llevado a cualquier materia de enseñanza, plasma el elenco de ideas, discursos y prácticas dominantes en la enseñanza dentro del marco de la cultura escolar. El código disciplinar comprende, pues, las especulaciones y retóricas discursivas, los contenidos de enseñanza y los arquetipos de práctica docente que se suceden en el tiempo. En cierto sentido, el código disciplinar encierra lenguajes, normas y convenciones socioculturales que designan la verdad, la legitimidad/ilegitimidad del saber escolar, a modo de los foucaultianos «regímenes de verdad», fundados en «sistemas de razón» de larga data que se incorporan como una segunda piel a las pautas de conducta profesional e individual de los docentes en los espacios educativos. En suma, este concepto actúa como llave heurística para desentrañar la prodigiosa magia que envuelve y oculta la naturaleza del conocimiento escolar.

Adelanté y expuse por primera vez tan estratégico hallazgo en una conferencia pronunciada en 1992 en la Universidad de Santiago de Compostela y fue motivo central en la tesis doctoral que presenté en 1997 en la Universidad de Salamanca ${ }^{40}$. Desde entonces tal artefacto conceptual ha gozado de una cierta proyección en España y más aún en América Latina ${ }^{4+}$. En cierto modo, pasadas algo más de dos décadas de su formulación académica como tesis de doctorado, su migración y

39 Bourdieu, P.: Las reglas del arte. Génesis y estructura del campo literario, Barcelona, Anagrama, 1995, p. 266.

${ }_{40}$ CuEsTA, R.: El código disciplinar de la Historia. Tradiciones, discursos y prácticas sociales de la educación histórica en España (siglos XVII-XX), Salamanca, Facultad de Educación de la Universidad de Salamanca, 1997 (disponible en www.nebraskaria.es). Este trabajo académico fue dirigido por José María Hernández, catedrático de Historia de la Educación en esa universidad.

${ }^{41}$ Sobre todo en Brasil, Colombia y Argentina. Como muestra del interés por mi trabajo, véase Pinheiro Cigales, M. y Martín Engeroff, A.: «Código disciplinar e Historia de las disciplinas escolares. Entrevista con Raimundo Cuesta», História da Educaçao, vol. 22 (2018), pp. 8-18. Disponible en htttp://dx.doi.org/I0.1590/2236-3459/75183 
aceptación entre las comunidades académicas ha sido relativamente apreciable, al punto de que ya es un lugar común citar su relevancia e influencia en los estados de la cuestión sobre la historia de las disciplinas escolares en España, aunque la aplicación de su aportación conceptual y metodológica no suele ser frecuente entre los estudiosos de este campo ${ }^{42}$.

En cuanto a las fuentes teóricas, no siempre se han comprendido bien las teselas que componen este concepto-mosaico y su significado. Si bien se mira, el calificativo «disciplinar», además de lo que tiene de imagen literaria y metafórica, supone sin duda un guiño de complicidad a las aportaciones de Foucault sobre el desenvolvimiento de la economía de poderes que rige la gestación de la modernidad. El paso de las sociedades punitivas a las sociedades disciplinarias coincide con la formación de los sistemas escolares nacionales y engarza directamente con la disposición y uso de las materias de enseñanza. En cuanto a «código», es término que ya por entonces estaba muy en boga en las ciencias humanas y, aunque con sentidos muy diversos, no dejaba de aludir a una genérica regulación, registro y sistematización de alguna faceta teórico-práctica de la vida social ${ }^{43}$. No obstante, por aquel entonces la mayor influencia sobre mi concepto-llave la ejerció la idea de la sucesión histórica de diversos modelos educativos bajo la forma de «códigos curriculares», tal como aparecen dibujados por Ulf P. Lundgren, pero eliminando toda huella formalista $y$, por consiguiente, dotando al sintagma código disciplinar de mayor plasticidad y de un alcance finalmente muy diferente ${ }^{44}$. Empero, cabe añadir que mi herramienta heurística clave va muy estrechamente vinculada a la idea de campo profesional, de suerte que una se inscribe sin esfuerzo en la otra, y ambas tienen como sustrato común una teoría de la acción en las instituciones educativas deudora de P. Bourdieu ${ }^{45}$. Y junto a código disciplinar y campo profesional, el tercero en discordia fue la incorporación de una teoría sobre los «modos de educación» ${ }^{46}$, cuya fuente de inspiración reside en la formidable obra de Carlos Lerena, el excelente teórico social que también impregna mi quehacer como telón de fondo. En realidad, si bien se mira, mi pesquisa sobre las disciplinas escolares se sostuvo sobre tres anclajes teórico-conceptuales, a saber: código disciplinar (una duradera tradición de discursos y prácticas), campo profesional (una teoría de la práctica docente en el contexto escolar) y modos de educación (una fórmula para comprender los dos anteriores conceptos en el tiempo largo de la cultura escolar y en la historia del desenvolvimiento de los sistemas educativos). Naturalmente, sigo pensando que todo este encofrado de categorías apenas trata de paliar la intrínseca debilidad del lenguaje humano para representar la realidad y sacar a las cosas de su mudez, como aludía en la primera parte de este escrito.

42 VIÑaO, A.: «La historia de las disciplinas escolares», Historia de la Educación, n. ${ }^{\circ} 25$ (2006), pp. 243-269. A partir de este artículo-bastidor el mismo autor ha proseguido escribiendo otros meritorios estados de la cuestión que sería prolijo enumerar aquí.

43 Por ejemplo, Bernstein, B.: Clases, códigos y control, I y II, Madrid, Akal, i988.

44 Lundgren, U. F.: Teoría del currículum y escolarización, Madrid, Morata, 1992.

45 Bourdieu, P.: Razones prácticas. Sobre la teoría de la acción, Barcelona, Anagrama, 1997.

${ }_{46}$ Lerena, C.: Escuela, ideología y clases sociales en España, Barcelona, Ariel, 1976. pedagogía 
Pero, como ya comenté, mi indagación, que tuvo una débil y esporádica vinculación universitaria, no se explicaría al margen de Fedicaria, la agrupación voluntaria de profesores españoles partidarios de un pensamiento crítico y de una acción docente del mismo signo, que se fundó en 1995. En ese marco nació el Proyecto Nebraska (2002-20I2), que, inspirado en algunas hipótesis y conceptos manejados en mi tesis doctoral, emprendí y proseguí con Juan Mainer y Julio Mateos. Su historia y sus frutos bibliográficos son de libre acceso en www.nebraskaria.es. Las tesis de Juan Mainer, presentada en la Universidad de Zaragoza en 2007, y la de Julio Mateos, leída en 2008 en la Universidad de Salamanca ${ }^{47}$, profundizaron y ensancharon a lo largo de una década mis indagaciones originarias. Al final, mi trabajo resulta una muestra del alcance limitado y de las dificultades proteicas y cada vez mayores para asentar una vía investigadora autónoma y crítica al margen de la universidad, porque, como es sabido, fuera de la Iglesia no hay salvación ${ }^{48}$.

En fin, durante toda mi investigación sobre la historia de las disciplinas escolares jamás dejé de ser profesor de historia en un instituto de educación secundaria. Allí intenté crear las condiciones para el ejercicio de un uso público y deliberativo de la historia, rompiendo o esquivando parcialmente los imperativos y constricciones del código disciplinar heredado, de modo que la enseñanza de esa disciplina llevara a poner sobre el tapete escolar esa clase de historia con memoria que reclama como postulados didácticos iniciales, insoslayables y estratégicos, problematizar el presente y pensar históricamente. Así, siempre entendí que la práctica de una historia crítica de la educación me llevaría como de la mano a propugnar una educación del mismo género siempre atenta y solidaria con la memoria de los vencidos ${ }^{49}$. Porque, si bien se mira, en ellos reside una fértil semilla epistemológica a la hora de comprender el pasado y, en consecuencia, de explicar nuestro presente y de imaginar nuestro futuro.

47 Y que dieron lugar a dos versiones en forma de libro, a saber, MAIner, J.: La forja de un campo profesional. Pedagogía y didáctica de las ciencias sociales en España, 1900-1970, Madrid, CSIC, 2009; y Mateos, J.: Genealogía de un saber escolar: el código pedagógico del entorno, Barcelona, Octaedro, 20II. Otra veta muy destacada, nacida a caballo entre Fedicaria y la Universidad de Cantabria, es la representada y encabezada por Alberto Luis Gómez y proseguida felizmente hoy por sus colegas Jesús Romero y Marta Estellés.

${ }^{8}$ Una crítica académica de mi obra puede verse en GonzÁlez Delgado, M.: «Notas para una evaluación de la historia del currículum: estudio de los procesos de legitimación y cambio», Tempora, n. ${ }^{\circ}$ II (2008), p. 43 [pp. 97-I34]. Este extenso artículo, avance de su posterior tesis de doctorado, ha sido precursor de otros textos en los que él solo, o en compañía de su colega Manuel Ferraz, redunda en una reescritura antisociológica de la historia de las disciplinas escolares.

49 Véase Cuesta, R.: Los deberes de la memoria en la educación, Barcelona, Octaedro, 2007. 
